\title{
Adverse Events Following Pneumococcal Vaccination among Infants attending Immunization Clinic at a Tertiary Hospital in Northern India
}

\section{Shweta Goswami ${ }^{1}$, Shefali Gupta ${ }^{2}$, Mitasha Singh ${ }^{3}$, Ekta Gupta ${ }^{4}$}

${ }^{1}$ Assistant Professor, Department of Community Medicine, ESIC Medical College and Hospital, Faridabad, 121001, Haryana; ${ }^{2}$ MBBS student (3rd Professional), ESIC Medical College and Hospital, Faridabad - 121001, Haryana;

${ }^{3}$ Assistant Professor, Community Medicine, ESIC Medical College and Hospital, Faridabad, 121001, Haryana ${ }^{4}$ Assistant Professor, Community Medicine, HIMSR, Jamia Hamdard, New Delhi

\begin{tabular}{|l|l|l|l|l|l|l|l|}
\hline Abstract & Introduction & Methodology & Results & Conclusion & References & Citation & Tables / Figures \\
\hline
\end{tabular}

\section{Corresponding Author}

Dr. Mitasha Singh, Assistant Professor, Department of Community Medicine, ESIC Medical College and Hospital, Faridabad - 121001, Haryana

E Mail ID: mitasha.17@gmail.com

回都回

\section{Citation}

Goswami S, Gupta S, Singh M, Gupta E. Adverse Events Following Pneumococcal Vaccination among Infants attending Immunization Clinic at a Tertiary Hospital in Northern India. Indian J Comm Health. 2020;32(3):569573.

Source of Funding: Nil Conflict of Interest: None declared

\section{Article Cycle}

Received: 07/06/2020; Revision: 25/06/2020; Accepted:02/09/2020; Published:30/09/2020

This work is licensed under a Creative Commons Attribution 4.0 International License.

\section{Abstract}

Background: Pneumococcal conjugate vaccine (PCV-13) has been introduced in India in a phased manner. In Haryana it was introduced in 2017. The adverse events following immunization (AEFI) with PCV in real community setting are yet to be detected. Objective: To calculate the incidence and associated factors for various AEFI after pneumococcal vaccination at a tertiary centre of Faridabad, Haryana. Methodology: The descriptive observational study was conducted from April through October 2019 at the immunization centre of a tertiary care centre of Faridabad, Haryana. Each dose of PCV-13 given to the infants attending immunization centre was the study unit. A telephonic contact was done within 24 hours, after 48 hours and between 5-7 days to enquire about any adverse events (minor \& major), if occurred. Results: A total of 135 PCV-13 doses were followed up for any AEFIs. 113 AEFIs (incidence: 67.3 per 100 dose) reported in 93 infants. Incidence of fever was 45 per 100 dose followed by tenderness and erythema (39 per 100 doses for each). Incidence of Swelling was 21 per 100 doses. Conclusion: Active surveillance and co administration of Pentavalent vaccine could have resulted in higher proportion of AEFIs.

\section{Keywords}

Side effects; AEFI; PCV-13; Haryana

\section{Introduction}

Pneumococcal disease remains a major cause of morbidity and mortality in children worldwide, particularly in countries where non-vaccine serotypes are common, and is a leading cause of vaccine preventable deaths in children under five years of age.(1)Depending on high morbidity and mortality due to $\mathrm{S}$. Pneumoniaunder-five children five Indian states, namely Himachal Pradesh, Haryana, Uttar Pradesh, Madhya Pradesh and Bihar, in 2017 introduced PCV-13.(2)
The safety of vaccines included in the Universal Immunization Programme (UIP) is of significant public health interest and is critical in maintaining confidence in the vaccine program. Rates of Adverse Events Following Immunisation (AEFI) detected through passive surveillance systems are likely to be lower than the true rate, due to under-reporting, but may still flag important AEFI for follow up.(3) AEFI detected following the introduction of a new vaccine into a population may be different to those detected in pre-implementation controlled clinical trials, as 
these are rarely powered sufficiently to detect rare AEFI. To fill this gap in knowledge we planned to carry out an observational epidemiological study.

\section{Aims \& Objectives}

To estimate the incidence and associated factors for various $A E F I$ after pneumococcal vaccination at a tertiary centre of Faridabad, Haryana.

\section{Material \& Methods}

Study design, duration and setting: The study was carried out in an Immunization clinic at a tertiary care centre of North India, during the period of AprilSeptember 2019 This tertiary centre caters to the population which is beneficiary of employees' state insurance act (ESI) and has income of less than 21000 INR per month. It was an observational descriptive study. The study was longitudinal in nature. It was a part of ICMR short term studentship programme for the year 2018-19.

Vaccine: The dosing schedule of PCV-13 in UIP is two primary doses at 6 weeks and 14 weeks, followed by a booster dose at 9 months. Pentavalent vaccine is also administered at 6 and 14 weeks. The dose of the PCV-13 is $0.5 \mathrm{ml}$ and to be administered by intramuscular injection in the antero-lateral aspect of the right mid thigh of infants.

Study population: Study population constituted of all the infants attending the immunization clinic for getting vaccines. All the infants who attended the immunization clinic during the study period and were eligible for pneumococcal vaccines were selected for the study. The infants were recruited irrespective of the dose of PCV being taken during the data collection period of three months. Exclusion criteria were as follows: consent not given by parent, were suffering from high grade fever, with history of convulsions, allergy, immune-compromised, having established acute illness, suffering from malignant conditions or any type of tumours, history of adverse/allergic effects with previous vaccines. Hence each dose of PCV-13 given to the infants attending immunization centre of the tertiary care centre was the study unit.

Ethical Considerations: Ethical clearance was taken from institutional ethical committee before starting the data collection (IEC no.134/A/AA/16/Academics/MC/2016/128).

Data Collection procedure: After screening the infants as per inclusion criteria at immunization centre for PCV-13 the informed consent was taken by the mother/father/guardians. Pre-vaccination counselling was done about the vaccine. After vaccination counselling was done to address the adverse events (minor \& major) and their management. A contact number was provided to the mother/father/natural guardians to report any adverse event noted. All those who consented for active surveillance of AEFI (part of current study) gave their contact numbers to the researcher. A telephonic contact was done within 24 hours (preferably within 8 hours), after 48 hours and between 5-7 days to know any adverse events (minor \& major), if occurred. In a case of any serious event, the patient was followed as per the AEFI guidelines of government of India.

Data and Statistical Analysis: Data was entered in Microsoft excel 2016 student's edition and statistical analysis was done using Epi info version 7. Any AEFI post PCV-13 dose was taken as outcome variable. Age, sex, birth weight, vital parameters and any illness preceding vaccination were taken as independent variables. Frequency with percentages was calculated. Chi-square test was used to compare categorical variable. Binary logistic regression was applied to obtain odds ratio.

\section{Results}

A total of 168 pneumococcal vaccine doses were given during the study period and 135 infants were followed up for the reporting of AEFIs. Hence the analysis of 135 has been presented.

Clinical history and examination of infant was done before giving vaccine. $23.75 \%$ infants at 1 st dose, $36.73 \%$ at 2 nd dose and $15.38 \%$ at 3 rd dose were suffering from ill health. Acute upper respiratory illness was reported as most common complaint at each dose. $6.25 \%, 4.08 \%$ and $2.56 \%$ infants were febrile at the time of 1st, 2nd \& 3rd dose.

A total of 113 AEFIs was reported in 93 infants. Incidence of all AEFls of pneumococcal vaccine administered was 74.2 per 100 doses after 1 st dose, 93.8 per 100 doses after 2 nd dose and 6.5 per 100 doses after booster dose. Overall Incidence was 67.3 per 100 doses [Table 1].

Most commonly reported AEFIs were fever and injection site reactions. Incidence of fever was 45 per 100 doses followed by tenderness and erythema (39 per 100 doses for each). Incidence of Swelling was 21 per 100 doses.All AEFIs reported were during first telephonic contact only i.e. within 24 hours of vaccine administration. During 2 nd and 3 rd telephonic contact after each dose, no fresh AEFIs 
was reported. Majority of infants with AEFIs were recovered within 24-48 hours of onset. Median duration of occurrence of adverse events in our study ranged from 3.5-4.5 hours across all doses. No major adverse events reported during study period. Bivariate analysis was conducted between socio demographic factors, vital parameters, illnesses, and infants (135) who were followed up for AEFls after PCV immunization. There was no significant association between gender of child with occurrence of AEFIs (OR 1.08 (95\% Cl: 0.572- 2.06)). Odds of occurrence of AEFIs was around twice higher among low birth weight infants (OR: 2.36 (95\% Cl: 0.6259.07)) as compared to normal weight and around 2.5 times higher among febrile infants as compared to afebrile ones (OR: 2.58 (95\% Cl: 0.28-23.76)). [Table 2]

\section{Discussion}

We conducted this active surveillance to estimate the AEFI after PCV-13 at an immunization centre of tertiary centre. Before immunization $23-36 \%$ of infants were found to be suffering from some minor illness at the time of immunization. Gadag et al,(4)and Perez-Trallero et al.,(5)in their studies on different vaccines reported the same.

Study reported high incidence of AEFIs per 100 doses administered after 1st and 2nd dose of pneumococcal vaccine (PCV-13). But with booster dose incidence was low. WHO states mild side effects such as soreness at the injection site, and transient fever of $\geq 39 \circ \mathrm{o}$ has been reported in less than $5 \%$ of vaccinees.(6)Incidence of fever was 45 per 100 doses administered in the current study. This was reported after 1st and 2 nd dose and none after booster dose. There can be multiple reasons for this. Firstly, this could be because active surveillance after immunization leads to reporting of all minor or major events which may or may not be chronologically related to immunization. Secondly, it is important to note that as DTP-HepB-Hib vaccine is be given at the same visit as $P C V$, reactions following immunization cannot usually be ascribed to one product or another. Shamshad et al., in a similar study on Pentavalent vaccine reported the incidence of fever to be as high as 50 per 100 doses.(7)Parents were well informed by the researcher that although this vaccine has an excellent safety profile, the side effects as stated above may occur.

Other symptoms of injection site reactions like tenderness (difficult limb movement), erythema, and swelling were reported between 20-40 episodes per 100 doses. This was supported by WHO findings which stated that local reactions (Pain, swelling, redness) is expected in $30-50 \%$ of cases. (6)Sebastian et al., conducted three year prospective study on active surveillance of AEFls following any vaccine among children under five years in Mysore from 2013-16. The incidence of AEFIs reported was $13.7 \%$; majority of which was attributed to Pentavalent (DPT+Hib+Hep B) vaccine. The most common AEFIs reported in a study by Sebastian et al., was fever, followed by injection site reactions similar to our study findings. (8) Evans in his study on compensation claimed by many countries for severe AEFIs reported DTP with the highest claims and still is the vaccine (even in combination vaccine) with the highest occurrence of AEFIs in young children.(9)

\section{Conclusion}

Incidence of all AEFIs of pneumococcal vaccine administered was 74.2 per 100 doses after 1 st dose, 93.8 per 100 doses after 2 nd dose and 6.5 per 100 doses after booster dose. High reporting rate for several common AEFI post Pneumococcal vaccine may be explained by co- administration of Pentavalent (DPT+ Hib+ Hep.B) but requires further investigation. There were no rare or serious AEFI reported that would require further investigation at this time.

\section{Recommendation}

A national AEFI database is need of the hour which will be helpful in understanding vaccine safety issues in the country to provide feedback to health care workers. This will help to maintain the confidence of public in vaccines.

\section{Limitation of the study}

The current study was limited to single centre due its short duration. Hence the generalisability of findings needs longer follow up.

\section{Relevance of the study}

Active surveillance of AEFI with Pneumococcal vaccine resulted in higher proportion of cases with fever, localised tenderness and erythema. The AEFI were mild in severity with higher occurrence during first and second dose.

\section{Authors Contribution}

Shweta Goswami and Shefali Gupta conceptualized the study. Ekta Gupta and Shweta Goswami conducted the literature search. Shefali Gupta 
collected the data. Data and statistical analysis was conducted by Mitasha Singh and Shweta Goswami. Shweta Goswami and Shefali Gupta prepared the first draft of manuscript. Ekta Gupta and Mitasha Singh reviewed and edited the final shape of manuscript.

\section{Acknowledgement}

The authors extend their gratitude to the parents of the children included in the study for their patience and cooperation. We would also thank the staff at the immunization clinic of the institute for their cooperation. The authors are also thankful to ICMRSTS-2018.

\section{References}

1. Rodgers GL, Klugman KP. The future of pneumococcal disease prevention.Vaccine. 2011 Sep 14;29 Suppl 3:C43-8. doi: 10.1016/j.vaccine.2011.07.047.

PMID:21896352.[PubMed]

2. Varghese $R$, Veeraraghavan B, Jeyaraman $Y$, Kumar G, Arora NK, BalasubramanianS. Pneumococcal conjugate vaccine rollout in India: Expectations and challenges.Indian J Med Microbiol. $2019 \quad$ Apr-Jun;37(2):141-146. doi:10.4103/ijmm.IJMM_19_320. PMID: 31745013. [PubMed].

3. Littlejohn ES,Clothier HJ, Perrett KP, Danchin $M$. Surveillance of adverse events following the introduction of 13 -valent pneumococcal conjugate vaccine in infants, and comparison with adverse events following 7-valent pneumococcal conjugate vaccine, in Victoria, Australia. Human Vaccines \&Immunotherapeutics. 2015; 11(7): 182835.

4. Ratnam S, West R, Gadag V. Measles and rubella antibody response aftermeasles-mumps-rubella vaccination in children with afebrile upper respiratorytract infection. J Pediatr. 1995 Sep;127(3):432-4. doi:10.1016/s00223476(95)70077-3. PMID: 7658276.[PubMed].

5. Cilla G, Peña B, Marimón JM, Pérez-Trallero E. Serologic response to measles-mumps-rubella vaccine among children with upper respiratory tract infection.Vaccine. 1996 Apr;14(6):492-4. doi: 10.1016/0264-410x(95)00234-r. PMID: 8782345.[PubMed].

6. WHO. Introduction of pneumococcal vaccine PCV13, A handbook for district and health facility staff. October 2013. Available from www.who.int/vaccines-documents. [Last accessed on 10th April, 2020]

7. Ahmad S, Pal J, Das A, Samanta S. Adverse events following immunization with pentavalent vaccine among infants attending the immunization clinic at a tertiary hospital in Eastern India. Int J Community Med Public Health 2017;4:2570-5.

8. Sebastian J, Gurumurthy P, Ravi MD, Ramesh M. Active surveillance of adverseevents following immunization (AEFI): a prospective 3-year vaccine safety study.Ther Adv Vaccines Immunother. 2019 Nov 21;7:2515135519889000. doi:10.1177/2515135519889000. PMID: 31799496; PMCID: PMC6873273.[PubMed]

9. Evans $\mathrm{G}$. Vaccine injury compensation programs worldwide. Vaccine. 1999;17(supplement 3):S25-S35

\section{Tables}

TABLE 1 INCIDENCE OF AEFIS PER 100 DOSES AFTER PNEUMOCOCCAL VACCINE ADMINISTRATION

\begin{tabular}{|l|l|l|l|l|}
\hline $\begin{array}{l}\text { Schedule } \\
\text { dose }\end{array}$ & Number $(\%)$ & $\begin{array}{l}\text { No. of AEFI reported } \\
(\%)\end{array}$ & $\begin{array}{l}\text { Incidence of AEFI per } 100 \\
\text { doses }\end{array}$ & $\begin{array}{l}\text { Chi square for trend, } \mathbf{p} \\
\text { value }\end{array}$ \\
\hline $\mathbf{1}^{\text {st }}$ dose & $89(52.97)$ & $66(58.41)$ & 74.2 & $29.33,<0.001$ \\
\hline $\mathbf{2}^{\text {nd }}$ dose & $48(28.57)$ & $45(39.82)$ & 93.8 & \\
\hline Booster dose & $31(18.45)$ & $2(1.77)$ & 6.5 & \\
\hline Total & 168 & 113 & 67.3 & \\
\hline
\end{tabular}

TABLE 2 RISK FACTORS IN INFANTS HAVING ANY AEFI WITHIN 24 HOURS OF ADMINISTRATION OF PNEUMOCOCCAL VACCINE

\begin{tabular}{|c|c|c|c|c|}
\hline \multirow[t]{2}{*}{ Variable } & \multirow[t]{2}{*}{ Category } & \multicolumn{2}{|c|}{ Any AEFI with any dose } & \multirow[t]{2}{*}{ OR(95\%Cl) } \\
\hline & & $\begin{array}{l}\text { Occurred } \\
(93)\end{array}$ & $\begin{array}{l}\text { Not Occurred } \\
(42)\end{array}$ & \\
\hline \multirow[t]{2}{*}{ Gender } & Male (79) & $53(67.09)$ & $26(32.91)$ & $1.08(0.57-2.06)$ \\
\hline & Female $(56)^{*}$ & $40(71.42)$ & $16(28.58)$ & 1 \\
\hline \multirow[t]{3}{*}{ Mothers' education } & Illiterate (11) & $8(72.73)$ & $3(27.27)$ & $0.39(0.13-1.21)$ \\
\hline & Primary + middle (26) & $18(69.23)$ & $8(30.77)$ & $0.62(0.28-1.37)$ \\
\hline & $\begin{array}{l}\text { High school and above } \\
(98)^{*}\end{array}$ & $67(68.37)$ & $31(31.63)$ & 1 \\
\hline \multirow[t]{2}{*}{ Birth order } & $1^{\mathrm{st}}(87)$ & $62(71.26)$ & $25(28.74)$ & $0.60(0.30-1.20)$ \\
\hline & $2^{\text {nd }}$ and Above $(48)^{*}$ & $31(64.58)$ & $17(35.42)$ & 1 \\
\hline \multirow[t]{2}{*}{ Mode of delivery } & Normal Vaginal (79) & $44(55.70)$ & $35(44.30)$ & $0.57(0.27-1.17)$ \\
\hline & LSCS + Assisted (56)* & $49(87.50)$ & $7(12.50)$ & 1 \\
\hline
\end{tabular}




\begin{tabular}{|c|c|c|c|c|}
\hline \multicolumn{4}{|c|}{ N JOURNAL OF COMMUNITY HEALTH / VOL 32 / ISSUE NO 03 / JUL- SEP 2020} & \multirow{2}{*}{$\begin{array}{c}{[\text { AEFI...] | Goswami S et a }} \\
1.93(0.36-10.2)\end{array}$} \\
\hline Gestational age at delivery & Full term (71) & $50(70.42)$ & $21(29.58)$ & \\
\hline & Preterm (57) & $41(71.93)$ & $16(28.07)$ & $1.62(0.31-8.59)$ \\
\hline & Post term (7)* & $2(28.57)$ & $5(71.43)$ & 1 \\
\hline \multirow[t]{2}{*}{ Birth weight (WHO class) } & Below -2SD (17) & $11(64.70)$ & $6(35.30)$ & $2.38(0.63-9.07)$ \\
\hline & $\begin{array}{l}\text { Between }-2 S D \text { to }+2 S D \\
(118)^{*}\end{array}$ & $82(69.49)$ & $36(30.51)$ & 1 \\
\hline \multirow[t]{2}{*}{ Temperature } & Febrile (5) & $4(80.00)$ & $1(20.00)$ & $\begin{array}{l}2.58(0.28- \\
23.76)\end{array}$ \\
\hline & Afebrile (130)* & $79(60.77)$ & $51(39.23)$ & 1 \\
\hline \multirow[t]{2}{*}{ Respiratory rate } & Fast (6) & $3(50.00)$ & $3(50.00)$ & $0.61(0.12-3.16)$ \\
\hline & Normal/Slow (129)* & $80(62.02)$ & $49(37.98)$ & 1 \\
\hline \multirow{2}{*}{$\begin{array}{l}\text { Any minor illness before the } \\
\text { scheduled dose }\end{array}$} & Yes (19) & $13(68.42)$ & $6(31.58)$ & $1.42(0.51-4.01)$ \\
\hline & No $(116)^{*}$ & $70(60.34)$ & $46(39.66)$ & 1 \\
\hline
\end{tabular}

